\title{
FUNGSI BAHASA DALAM SASTRA LISAN KABHANTI GAMBUSU PADA MASYARAKAT MUNA
}

\section{THE FUNCTION OF LANGUAGE IN ORAL LITERATURE OF KABHANTI GAMBUSU IN MUNA COMMUNITIES}

\author{
Hadirman \\ Institut Agama Islam Negeri (IAIN) Manado \\ hadirman@iain-manado.ac.id \\ Hardin \\ Universitas Halu Oleo Kendari \\ hardinatty@yahoo.co.id \\ Musafar \\ Institut Agama Islam Negeri (IAIN) Manado \\ musafarmusafar@iain-manado.ac.id
}

\begin{abstract}
Muna language as local language which belong to Muna community in Muna Regency Southaeast Province, has communnication and culture dimenssion. Communicative dimension in function as massege transmision. while, culture dimenssion, language as a medium to ekspress a culture meaning. The purpose this article is to explore the function of language in the oral literacy kabhanti gambusu. The method used in this research is descriptive-qualitative. The results showed that ekspression of language and culture in orally literacy text kabhanti gambusu has function. Function of language in to oral literacy kabhanti gambusu such as there function, are information function, interactive function, and imaginative function. The function of language in the oral literacy kabhanti gambusu contains meaning related to local beliefs/ religious, character education, social solidarity, ethics, aesthetics, and romance.
\end{abstract}

Keywords: language function, oral literacy, kabhanti gambusu, Muna community

\begin{abstract}
Abstrak
Bahasa Muna sebagai bahasa daerah masyarakat Muna di Kabupaten Muna Provinsi Sulawesi Tenggara mempunyai dimensi komunikatif dan dimensi budaya. Dimensi komunikatif melihat bahasa dalam fungsinya sebagai transmisi pesan, sedangkan dimensi budaya masyarakat, bahasa sebagai wahana untuk mengekspresikan makna budaya. Tujuan penulisan artikel ini untuk mengeksplorasi fungsi bahasa dalam sastra lisan kabhanti gambusu. Metode yang digunakan dalam penelitian ini adalah deskriptifkualiatif. Hasil penelitian menunjukkan bahwa cerminan bahasa dan budaya pada teks sastra lisan kabhanti gambusu mempunyai fungsi bahasa. Fungsi bahasa yang terdapat dalam sastra lisan kabhanti gambusu terdiri atas tiga fungsi, yakni informatif, interaktif, dan imajinatif. 2) Fungsi bahasa dalam sastra lisan kabhanti gambusu mengandung makna yang berkaitan dengan kepercayaan lokal/religius, pendidikan karakter, solidaritas sosial, etika, estetis, dan percintaan.
\end{abstract}

Kata kunci: fungsi bahasa, sastra lisan, kabhanti gambusu, masyarakat Muna 


\section{Pendahuluan}

Sastra lisan di Kabupaten Muna tidak asing lagi bagi masyarakat pemiliknya karena beberapa sastra lisan merupakan hiburan dalam acara-acara adat. Sastra lisan kabbanti gambusu dimanfaatkan masyarakat Muna untuk memelihara budaya serta media pendidikan budaya bagi generasi muda. Hanya saja, generasi muda sebagai ahli waris sastra lisan ini, kini mereka tidak tertarik lagi untuk mempelajari sastra lisan kabhanti gambusu. Selain mereka tidak terbiasa lagi menggunakan wamba wuna 'bahasa Muna' dalam ranah-ranah pemakaian bahasa Muna (ranah keluarga dan adat), juga tidak berminat belajar memetik kambusu sebagai media untuk mementaskan sastra lisan kabhanti gambusu (band. Hadirman \& Ardianto, 2016).

Sastra lisan kabhanti gambusu bila dicermati dari aspek fungsinya, memiliki fungsi tersendiri bagi penutur bahasa Muna. Bahasa Muna atau wamba wuna dalam konteks sastra lisan Muna adalah sebagai pendukung dan media pengungkapnya, bahkan hingga sekarang masih dipakai sebagai alat komunikasi bagi masyarakat Muna (Hadirman, 2016:19; Hadirman dan Ardianto, 2016: 2).

Kabhanti gambusu merupakan salah satu sastra lisan yang dimiliki masyarakat Muna yang dipertunjukkan di hadapan khalayak dengan menggunakan alat musik tradisional gambusu 'gambus'. Pengertian yang dikemukakan olehHadirman dan Ardianto (2016:3), kabhanti gambusu adalah pantun yang dinyanyikan dengan diiringi irama gambus serta botol kosong, paku, atau pemukul lainnya. Antara pemantun, saling berbalas pantun dalam menyampaikan pikirannya. Seorang pemantun bebas mengeksplorasi gagasannya. Bahkan, Ia dapat memengaruhi perasaan dan pemikiran pendengarnya (Hardin dan Hadirman, 2017:146). Biasanya, inspirasi didapatkan pemantun oleh adanya pengetahuan lokal yang berkaitan dengan budaya Muna. Ungkapan tersebut, selain berfungsi untuk melahirkan gubahan teks dalam kabhanti, juga terdapat fungsi-fungsi bahasa yang dikemukakannya.

Dinamika sastra lisan ini banyak dipandang sebagai suatu yang statis dan kurang mampu memberikan kontribusi dalam pengembangan masyarakat. Bahkan, sastra lisan ini mulai ditinggalkan generasi ahli warisnya. Akan tetapi, sastra lisan yang hidup dan berkembang pada masyarakat Muna memiliki fungsi. Fungsi yang dimaksud adalah berkaitan dengan fungsi penggunaan bahasa dalam sastra lisan. Fungsi tradisi lisan kabhanti gambusu pada masyarakat Muna dimanfaatkan untuk menyampaikan informasi, media kontrol sosial, dan menghadirkan aspek keindahan (puitik).

Artikel ini bertujuan untuk mengeksplorasi fungsi bahasa yang tercermin dalam teks sastra lisan kabhanti gambusu pada masyarakat Muna. Dengan mengkaji fungsi bahasa yang terkandung di dalam tradisi lisan, makna dan pengetahuan lokal yang terkandung di dalamnya dapat dieksplorasi. Dengan mengeksplorasi fungsi bahasa yang terkandung dalam sastra lisan ini, tidak saja berkontribusi dalam pemertahanan kearifan dalam bahasa Muna, tetapi juga dapat memberi kontribusi dalam bidang kajian sastra lisan Muna dan pemertahanan bahasa Muna.

\section{Teori Fungsi Bahasa}

Fungsi bahasa telah didefinisikan oleh para ahli dengan berbagai sudut pandang. Sebagaimana dikemukan oleh Luardini (2007:24) bahwa dewasa ini pembahasan tentang fungsi bahasa telah banyak dikatakan oleh ahli. Fungsi bahasa oleh sebagian ahli dianggap sama dengan penggunaan bahasa.

Bahasa memiliki seperangkat fungsi, baik sosial, budaya, maupun religius. Fungsi bahasa tidak hanya tampak pada peranannya sebagai media pengungkap nilai-nilai sastra lisan, tetapi berkaitan pula dengan pendayagunaan nilai dan 
norma antargenerasi (Halliday, 1979:12). Kenyataannya, bahwa sastra lisan kabhantigambusu menggunakan bahasa sebagai media instrumental utama dalam mentrasmisikan nilai-nilai budaya lokal.

Bahasa bernilai dan berfungsi bagi kehidupan manusia dan masyarakat, termasuk pengungkap sastra lisan. Fungsi bahasa dalam sastra lisan tampak nyata karena bahasa digunakan untuk tujuan komunikasi dan interaksi sosial. Tujuan penggunaan bahasa berkaitan dengan sistem gagasan, harapan-harapan, dan ideologi (band. Hymes, 1974:2-3). Menurut Hymes (1974:43), ungkapan bahasa memiliki dua fungsi utama, yakni fungsi struktural dan fungsi penggunaan. Fungsi struktural berkaitan dengan wujud kebahasaan dan fungsi penggunaan berkaitan dengan dunia luar bahasa. Namun, kedua fungsi bahasa tersebut saling bertalian satu dengan lainnya.

Shipley dalam Effendy (2006) yang mengartikan sastra lisan sebagai jenis karya sastra yang penyampaiannya dituturkan dari mulut ke mulut, yang tersebar secara lisan, bersifat anonim, dan menggambarkan kehidupan masyarakat masa lampau. Sastra lisan adalah suatu karya sastra yang dihasilkan/diciptakan dan dituturkan secara lisan dengan mulut, baik dalam suatu pertunjukan seni maupun di luarnya (Hutomo, 1991:10). Sementara itu, Finnegan (1978:15) menguraikan bahwa untuk mengetahui jenis sastra lisan memerlukan pengetahuan tentang keseluruhan latar belakang sastra, dan sosial budaya yang meliputi pula penampilan, audiens, dan konteks.

Bahasa memang telah disadari memiliki fungsi yang amat penting dalam kehidupan masyarakat sebagai alat berpikir, alat untuk merekam pengalaman masa lalu, sebagai wadah rasa yang fungsinya paling tampak dalam kehidupan masyarakat sebagai media perhubungan (Jendra, 1991:28).

Halliday dalam karyanya yang berjudul Exploration in the Function of Language (1977:43) membagi fungsi bahasa menjadi enam bagian, yaitu fungsi emotif, konotatif, kontekstual, pesan, kontak, dan kode. Pembagian fungsi bahasa itu dirasakan masih tumpang tindih sehingga beliau akhirnya mengerucutkan pembagian itu menjadi tiga bagian yang lebih bersifat penggabungan dari keenam pembagian itu, yakni (1) Fungsi ideasional (fungsi ini mencakup pemahaman pengetahuan, pengertian, cita, pikiran, perasaan yang berhubungan dengan sikap perilaku seseorang atau masyarakat); (2) Fungsi antarpribadi/interpersonal (bahasa berfungsi untuk mengadakan hubungan (catatan, pembagian ketiga tidak ditulis oleh penulis)

Teori fungsi bahasa dikemukakan Roman Jakobson (Zaimar, 2008:345-346) dikelompokkan menjadi: (1) fungsi ekspresif, yakni apabila bahasa digunakan untuk menekankan pikiran dan perasaan penutur; (2) fungsi konatif, apabila tekanan tutur ada pada si penerima, yaitu apabila di dalam tuturan. Teori yang digunakan untuk menganalisis fungsi bahasa yang terkandung dalam sastra lisan kabhanti gambusu adalah yang dikemukakan oleh Halliday dan Hasan (1985) dalam Luardini (2007:24) fungsi bahasa terdiri atas (1) informative uses (fungsi informatif), (2) interactive uses (fungsi interaktif), yang terdiri atas control other (kontrol sesama), mutual support (saling mendukung), dan express self (ekspresi diri), (3) imaginative uses (fungsi imaginatif) terdiri atas (a) ritual (ritual), dan (b) poetic (puisi).

\section{Metode Penelitian}

Penelitian ini dilakukan dengan pendekatan deskriptif-kualitatif. Prosedur dan tahapan penelitian mencakup tata cara pemerolehan data, analisis data, dan penyajian analisis data penelitian. Data utama penelitian ini adalah bahasa dalam wujud wacana yang digunakan pemantun sastra lisan kabhanti gambusu. Teks-teks yang jadikan objek dalam penelitian ini adalah teks-teks sastra lisan kabhanti gambusu pada masyarakat Muna. 
Data teks-teks sastra lisan kabhanti gambusu diperoleh melalui observasi (pengamatan) terhadap pementasan kabhanti gambusu, perekaman pementasan kabhanti gambusu untuk memperoleh data tuturan (lisan), dan studi kepustakaan berupa hasil-hasil penelitian dan artikel terkait dengan sastra lisan kabhanti gambusu.

Wacana atau teks-teks sastra lisan kabhanti gambusu sebagai wujud bahasa berfungsi dan bermakna secara kontekstual. Menurut Hoed (2008:192), analisis sastra lisan mengungkapkan apa yang terkandung di dalamnya, yakni hal-hal yang terlahir dan mentradisi dalam suatu masyarakat. Analisis ditekankan pada isi teks. Kaidah lain yang digunakan dalam analisis sastra lisan dengan mengkaji cara teks-teks lisan yang dihasilkan oleh penutur (Koster, 2008:35). Berdasarkan pandangan di atas, cara kerja penelitian ini dilakukan sebagai sebagai berikut.

(1) Analisis tidak difokuskan pada konteks, tetapi lebih ditekankan pada analisis teks sastra lisan kabhanti gambusu yang dipentaskan dalam kehidupan masyarakat Muna.

(2) Teks sastra lisan kabhanti gambusu dikumpulkan melalui perekaman pada masyarakat pemiliknya (pemantun) saat sastra lisan ini dipentaskan.

(3) Teks sastra lisan kabhanti gambusu yang direkam kemudian dilakukan transkripsi dari bahasa Muna ke bahasa Indonesia yang mudah dipahami dengan menggunakan Kamus Muna-Indonesia karangan Rene van den Berg dan La Ode Sidu (2000).

(4) Setelah ditranskripsi, teks-teks sastra lisan kabhanti gambusu yang terpilih dilakukan kajian berupa pengategorian berdasarkan teori fungsi bahasa.

Setelah data dikumpulkan, dikategorisasi, kemudian dianalisis secara deskriptif berdasarkan teori fungsi bahasa yang terkandung di dalamnya. Setelah disajikan dalam bentuk ketegori fungsi bahasa kemudian dilakukan penafsiran kandungan makna di dalam teks-teks sastra lisan tersebut. Analisis data dan penafsiran disajikan dengan narasi yang ringan dan mudah dipahami.

\section{Fungsi Bahasa pada Teks Sastra Lisan Kabhanti Gambusu}

Ekspresi bahasa yang tercermin dalam teks kabhanti gambusu mempunyai beberapa fungsi, yaitu fungsi informatif tentang pengetahuan lokal dan alat musik tradisional; fungsi interaktif terdiri atas fungsi kontrol sesama, saling mendukung, dan eskpresi diri; dan fungsi imaginatif terdiri atas fungsi ritual dan puitik. Fungsi bahasa yang terdapat dalam sastra lisan kabhanti gambusu ditampilkan berikut ini.

\subsection{Fungsi Informatif}

Bahasa digunakan untuk menyampaikan informasi dan menciptakan komunikasi (Soga dan Hadirman, 2018:55). Fungsi informatif bahasa dipahami sebagai fungsi dalam memberikan informasi mengenai sesuatu hal yang berkaitan dengan sosio-kultural masyarakat pendukungnya. Fungsi bahasa dalam tulisan ini dititikberatkan pada konten bahasa yang akan dituturkan dalam sastra lisan kabhnati gambusu. Berdasarkan kandungan teks-teks sastra lisan kabhanti gambusu, fungsi informasi, yakni seperti uraian berikut.

\subsubsection{Fungsi Informatif tentang Pengetahuan Lokal}

Fungsi informatif teks sastra lisan kabhanti gambusu mengungkapkan makna pengetahuan lokal. Fungsi informatif pada teks kabhanti gambusu yang berkaitan dengan pengetahuan lokal, yaitu menyangkut praksis budaya lokal masyarakat Muna dalam memanfaatkan pengetahuan lokal sebagai sampiran sastra lisan kabhanti gambusu. 
Pengetahuan lokal yang terekspresi dalam sampir- bahwa sejak zaman dahulu masyarakat Muna mean sastra lisan kabhanti gambusu menyiratkan makna miliki pengetahuan lokal.

1) Wora anabi nekantisele (1)

Nekatinsele samentaeno (2)

One morae nantolele (3)

Dabu dua bhela bhaindo (4)

2) Koe ngkeameri meria (1)

Koe ngkameri meria (2)

Idi pande ngkororoa (3)

Idi pande ngkororoa (4)

3) Koro kororo ngkeanau (1)

Koro kororo ngkanau (2)

Atumapigho kundomu (3)

Atumapigho kundomu (4)

4) Bhara omafa ngkanau (1)

Bhara omafa ngkanau (2)

Sawurondo ngkabunako (3)

Sawurondo ngkabunako (4)

5) Laba apoguru bente (1)

Laba apoguru bente (2)

Asarangka sawurondo (3)

Asarangka sawurondo (4)
Saya melihat anak dikantisele (1)

Dikantisele di pagi hari (2)

Kalau tampaknya tersiar (3)

Lebih baik sama orang lain (4)

Jangan takut-takut (1)

Jangan takut-takut (2)

Saya pintar memanggil roh (3)

Saya pintar memanggil roh (4)

Panggil-panggil roh saya (1)

Panggil-panggil roh saya (2)

Saya lekati punggungmu (3)

Saya lekati punggungmu (4)

Kira-kira saya dibuat apa (1)

Kira-kira saya dibuat apa (2)

Saya bersembunyi seperti roh (3)

Saya bersembunyi seperti roh (4)

Lebih baik belajar penjaga diri (1)

Lebih baik belajar penjaga diri (2)

Saya menyamar tidak tampak (3)

Saya menyamar tidak tampak (4)
Ungkapan (1), (2), dan (3) berisi kepercayaan lokal masyarakat Muna terhadap kantisele (ritual memanggil roh). Ungkapan (1) berisi kepercayaan pada ritual kantisele 'ilmu pemanggil roh' direpresentasikan ungkapan wora anabi nekantisele, nekantisele samentaeno'saya melihat anak di-kantisele, di-kantisele di pagi hari. Kantisele biasanya dilakukan pada anak yang tidak enak makan atau menderita penyakit lain yang tidak dapat disembuhkan dengan ilmu medis. Biasanya, dalam masyarakat Muna penyakit tersebut diobati dengan memanggil rohnya yang hilang.

Kepercayaan terhadap roh ini pada masyarakat Muna masa lalu cukup kuat, terutama di pedesaan. Hal ini tampak pada kebiasaan masyarakat Muna yang memercayai ritual memanggil roh orang yang sakit agar sembuh. Kepercayaan pada perginya roh harus di-kantisele. Ritual memanggil roh yang hilang disebut kantisele. Kantisele dilakukan selama tiga malam (biasanya dilaksanakan antara pukul 17.00-19.00). Proses pelaksanaannya dengan meniup ubun-ubun, telinga, telapak tangan hingga siku, dan lutut hingga telapak kaki yang diulang sampai tiga kali. Sambil meniup bagian-bagian tubuh tersebut, pande kantisele ${ }^{1}$ mengucapkan kororo...kororo...

Pemakaian kata yang berkaitan dengan pengetahuan lokal adalah kata ntonuana 'roh' (roh manusia) kantisele 'kantisele' (ritual mengembalikan roh yang hilang). Penggunaan leksikon yang

\footnotetext{
${ }^{1}$ Orang yang dapat mengobati orang yang sakit karena ruhnya meninggalkan tubuhnya.
} 
berkaitan dengan dunia roh merupakan bukti nyata bahwa manusia sangat memercayai hal itu. Leksikon ntonuana 'roh' pada masyarakat Muna biasanya sangat dekat dengan leksikon kororoa 'memanggil roh'. Kororoa 'memanggil roh' dilakukan dalam upacara kantisele 'ilmu memanggil roh yang hilang'. Seseorang di-kantisele 'dipanggil rohnya' apabila orang tersebut tidak ada nafsu makan. Apabila gejala-gejala itu muncul, suatu pertanda nokala tonuanano 'pergi rohnya' sehingga harus di-kantisele. Ilmu kantisele dilakukan dengan cara kororoa 'memanggil roh

Ungkapan (4) dan (5) bermakna kepercayaan pada ilmu sawurondo (menghilangkan diri) dan ilmu bente 'penjaga diri'. Hal ini direpresentasikan ungkapan sawurondo ngkabunako 'saya bersembunyi seperti roh', laba apoguru bente 'lebih baik belajar ilmu bente', dan ibintu mebente sugimo 'kamu berlindung diri'. Kepercayaan sawurondo adalah kepercayaan tentang menghilangkan diri dalam sekejap dan kepercayaan pada bente, berkaitan dengan ilmu penjaga diri.

\section{Informasi Alat Musik Tradisional}

Alat musik yang digunakan pada acara-acara budaya cukup banyak, salah satunya gambusu (alat musik gambus). Teks sastra lisan kabhanti gambusu memberikan informasi tentang alat musik tradisional yang menjadi media tradisional masyarakat Muna. Bahkan, dijelaskan dengan bagian tubuh manusia yang digunakan untuk membunyikan dan mengatur irama seperti tampak di bawah ini.
6) Ane merapa ane merapa gambusu (1) Kalau memetik memetik gambus (1) Merapa bhela merapa bhetangkidi (2) Memetik kasian dengan jari kecil(2) Aforatoko koemo metete buku (3) Saya beri tahu jangan bertahan diri (3) Amateangko amateangko ndoidi (4) Saya akan mati untukku (4)

Ungkapan (6) menggambarkan alat musik tradisional yang dilukiskan dalam kalimat (1-2) adalah alat musik tradisional, yakni gambusu 'alat musik gambus' yang biasa dipetik dengan jari kecil. Alat musik tradisional gambusu 'gambus' dimanfaatkan pemantun untuk menjadi sampiran kabhanti gambusu. Pada kalimat selanjutnya menunjukkan isi kabhanti, yakni sebagai ungkapan perasaan (percintaan) pada pebhanti laki-laki kepada pebhanti perempuan, bahwasanya "janganlah bertahan diri, terimalah curahan hati saya, saya akan mempertaruhkan nyawa untukmu" (pebhanti perempuan). Ungkapan (6) di atas memiliki makna percintaan (cinta kasih).

\subsection{Fungsi Interaktif}

Fungsi interaktif dalam suatu bahasa tercermin pada dampak dari pemakaian bahasa itu sendiri. Fungsi tersebut terbagi dari tiga kategori, yakni fungi kontrol sesama, fungsi saling mendukung, dan fungsi ekspresi diri (Luardini, 2007). Teks kabbanti gambusu memiliki ketiga fungsi tersebut.

\subsubsection{Fungsi Kontrol Sesama}

Teks-teks kabhanti gambusu melukiskan hubungan manusia dengan sesamanya yang mengemukakan perlunya hubungan yang harmonis. Dalam teks-teks kabhanti gambusu terkandung harapan akan adanya harmoni sesama dan kontrol sesama, Dengan demikian, teks-teks kabhanti gambusu secara tidak langsung menggambarkan harmoni sesama dan kontrol sesama. Kontrol sesama pada teks kabhanti gambusu ditunjukkan oleh modalitas (modulasi dengan bentuk negasi dan imperatif) yang disertai sirkumstan tertentu dengan maksud sebagai larangan atau tindakan yang ditabukan. 
7) Koe kamba kambagea (1)

Koe kamba kambagea (2)

Kambage domateane (3)

Kambage domateane (4)
Janganlah bersenda gurau (1)

Janganlah bersenda gurau (2)

Senda gurau bisa mati (3)

Senda gurau bisa mati (4)
Ungkapan (7) di atas menyiratkan bahwa dalam interaksi sesama manusia, boleh bersenda gurau asalkan tidak berlebihan. Dengan lidah, manusia dapat membuat orang celaka. Bahkan, dalam ajaran agama Islam, bersenda gurau diperbolehkan asalkan tidak berlebihan. Hanya saja, bersenda gurau dalam urusan pribadi orang, perlu dihindari karena dapat menyebabkan orang lain tersinggung dan sakit hati. Kalau orang sudah tersinggung, dapat menyebabkan terjadinya pertikaian dan permusuhan. Ungkapan (7) bermakna solidaritas sosial, yakni menciptakan suasana harmoni dalam kehidupan sosialkemasyarakatan.
8) Ane okambore mbore (1)

Netaabimo netaabimo ngkoise (2)

Ane okambore mbore (3)

Netaabimo netaabimo ngkoise (4)
Kalau kamu agak bodoh-bodoh (1)

Lebih baik lebih baik janganlah (2)

Kalau kamu agak bodoh-bodoh (3)

Lebih baik lebih baik janganlah (4)
Ungkapan kabhanti gambusu (8) terdapat kosakata ngkoise 'janganlah' adalah efek dari pemakaian modalitas dalam kalimat pada teks kabhanti gambusu. Di balik pemakaian modalitas tersebut, tersimpan pesan untuk saling mengontrol atau mengukur kemampuan dirinya sebelum bersikap atau berbuat. Dengan demikian, larangan tersebut untuk mengontrol atau saling mengingatkan sesama manusia untuk tidak melakukan sesuatu yang tidak diketahui atau disanggupinya. Hal ini menunjukkan bahwa sastra lisan kabhanti gambusu dapat menjadi sarana untuk "membentuk karakter anak/masyarakat yang mendengarnya agar dapat berbudi pekerti luhur" (Ardianto, dkk. 2018).

\subsubsection{Fungsi Saling Mendukung}

Dampak pemakaian bentuk modalitas dalam suatu bahasa, selain memunculkan fungsi kontrol sesama, dapat pula ditempatkan pada fungsi saling mendukung. Keterkaitan larangan/tindakan yang dapat menyebabkan keretakan sosial, seperti pada teks kabhanti gambusu (7) dan (8) di atas merupakan dukungan dalam hal etika bertutur kata pada masyarakat Muna yang tergolong beradab. Fungsi tindakan untuk tidak memaki dan bertutur kata santun merupakan dukungan untuk menciptakan harmoni sosial dalam masyarakat (Hadirman, 2018). Fungsi menciptakan harmoni sosial tersebut mempunyai efek pada masyarakat Muna dalam mendukung tingkah laku mereka sesama manusia. Hal ini selaras dengan apa yang dikatakan Jendra (1999:6), yakni berbicara adalah bagian yang tidak terpisahkan dari berbahasa. Menurut Jendra (1999:8), kata-kata adalah demikian penuh kekuatan sehingga menunjukkan karakter seseorang, menampilkan kepribadiannya, mendidik yang lain, serta menyampaikan pengalaman. Maka, berhati-hatilah dengan kata-kata, tergelincir ketika berjalan, sakitnya dapat diobati, tetapi tergelincir ketika berbicara, sakitnya tak tersembuhkan (Jendra, 1999:8).

\subsection{Fungsi Imaginatif}

Fungsi imaginatif dibagi dalam dua kategori fungsi, yaitu fungsi ritual dan fungsi puitik 
(Luardini, 2007). Fungsi ritual bahasa dikemukakan Halliday dan Hasan (1985:17). Teks kabhanti gambusu memiliki fungsi tersebut yang dikemu- kakan dalam bahasa yang mudah dipahami. Teks sastra lisan kabhanti gambusu berikut mempunyai unsur ritual dan puitis di dalamnya.
9)

$$
\begin{aligned}
& \text { Laba apoguru bente (1) } \\
& \text { Laba apoguru bente (2) } \\
& \text { Asarangka sawurondo (3) } \\
& \text { Asarangka sawurondo (4) }
\end{aligned}
$$

10) Ibintu mebente sugimo (1)

Ibintu mebente sugimo (2)

Atumewoko noafa (3)

Atumewoko noafa (4)

11) Lebe naebasa bae (1)

Lebe naebasa hae (2)

Ane pae danseise (3)

Ane pae danseise (4)

12)

\section{Lebe naebasa dhoa (1) \\ Lebe naebasa dhoa (2) Akumai tangkidiko (3) Akumai tangkidiko (4)}

Lebih baik belajar penjaga diri (1)

Lebih baik belajar penjaga diri (2)

Saya menyamar tidak tampak (3)

Saya menyamar tidak tampak (4)

Kamu berlindung diri (1)

Kamu berlindung diri (2)

Saya jaga kamu (3)

Saya jaga kamu (4)

Si Lebe membaca apa (1)

Si Lebe membaca apa (2)

Kalau tidak seia sekata (3)

Kalau tidak seia sekata (4)

Si Lebe membaca doa (1)

Si Lebe membaca doa (2)

Saya kait jari kecilmu (3)

Saya kait jari kecilmu (4)
Ungkapan (9-12) di atas menyiratkan beberapa ritual yang direkam di dalam teks kabhanti gambusu. Adanya ungkapan bente, sawurondo, lebe, dan dhoa menunjukkan adanya fungsi ritual dalam teks kabhanti gambusu, seperti kehadiran ungkapan laba apoguru bente 'lebib baik saya belajar ilmu bente' pada tuturan (9), asarangka sawurondo 'saya menyamar agar tidak tampak' pada ungkapan (10), kata bente 'ilmu kanuragan' dan sawurondo 'ilmu menghilangkan diri dari penglihatan' yang dilaksanakan dengan ritus-ritus tertentu yang dilakukan masyarakat Muna pada masa dahulu kala. Kemudian terdapat pula ungkapan lebe naebasa hae Lebe akan membaca apa', ungkapan (11) dan lebe naebasa dhoa 'lebe membaca doa'. Kata lebe merupakan panggilan seorang dewasa dalam sara Muna, yang bertugas untuk memimpin ritual-ritual keagamaan dan adat. Hal ini diperjelas pada ungkapan kabhanti
(12), yakni lebe naebasa dhoa 'lebe akan membaca doa'. Ungkapan-ungkapan di atas menggambarkan teks sastra lisan kabhanti gambusu yang berkaitan dengan aspek magis (ritual). Koster (2008:48) menegaskan bahwa teks-teks sastra lisan merupakan khazanah kaya-raya yang di dalamnya masih banyak tersimpan realitas kehidupan pada suatu masa dahulu.

Fungsi puitis ini memperlihatkan penonjolan pesan melalui berbagai cara, baik leksikal, gramatikal, maupun fonologis (Hoed, 2008:187). Fungsi puitik dalam teks kabhanti gambusu adanya pengucapan bait-bait puisi yang mirip dengan baitbait puisi yang berulang. Repetisi klausa-klausa tersebut dikategorikan sebagai fungsi puitis. Perulangan tersebut seperti terlihat pada contoh (9-12). Ungkapan tersebut tampak paralelisme, yakni ungkapan (9-10) diulang pada ungkapan (11- 
12). Adanya paralelisme tersebut untuk memperindah bunyi dan menegaskan makna estetis. Keindahan dalam teks kabhanti gambusu bisa melahirkan kedamaian, ketenangan, dan kesejukan dalam jiwa dan pikiran. Dengan demikian, keindahan dalam teks kabhanti gambusu dapat dijadikan sebagai tempat untuk membangun harmoni sosial, berintrospeksi diri dan menghadirkan ketenangan bagi yang mendengarnya. Fungsi puitik yang lain terjadi pada ungkapan yang diujarkan secara berulang (paralel). Ungkapan tersebut mengandung bahasa puitis, yakni bahasa yang bentuknya diutamakan dan ditonjolkan untuk memberikan dampak estetis (Kadarisman, 2008:220).

Fungsi puitis yang berkaitan dengan dinamika fonologis, tampak pada ungkapan naepae danseise kalau tidak seia sekata'. Keindahan bunyi sonoran /n/ makin memperindah bunyi ungkapan tersebut. Kata danseise 'seia sekata' dalam bahasa keseharian diucapkan daseise 'seia sekata'. Hadirnya bunyi sonoran /n/dalam teks kabhanti gambusu berfungsi untuk memperindah kata. Hal ini menunjukkan bahwa sastra lisan kabhanti gambusu selain mengandung pesan yang komunikatif, juga mengandung kekuatan kata, termasuk pula menghadirkan makna estetis (band. Hadirman dan Ardianto, 2016:5).

\section{Simpulan}

Berdasarkan hasil eskplorasi terhadap teksteks sastra lisan kabhanti gambusu pada masyarakat Muna berdasarkan fungsi bahasa yang dikemukan Halliday dan Hasan (1985), ternyata terdapat pula dalam fungsi bahasa yang tercermin melalui teks sastra lisan kabhanti gambusu. Fungsi bahasa yang terdapat dalam teks tradisi lisan kabhanti gambusu, yakni pertama, fungsi informatif tentang adatistiadat, pengetahuan lokal. Makna yang tercemin dalam fungsi bahasa ini adalah makna terungkapnya kepercayaan lokal (kantisele, sawurondo, dan bente), dan percintaan (curahan hati). Kedua, fungsi interaktif direalisasikan dalam fungsi kontrol sesama manusia, manusia dengan penonton kabhanti gambusu. Makna yang dominan dalam fungsi bahasa ini adalah makna solidaritas sosial, pendidikan karakter, dan etika bertutur kata. Ketiga, fungsi imaginatif dibagi dalam fungsi religi dan puitik. Fungsi puitik dalam kabhanti gambusu ditemukan dalam bentuk pengulangan klausa dan ungkapan dengan paralelisme klausa. Paralelisme tersebut, dapat menegaskan makna yang terkandung di dalamnya. Makna yang terepresentasi dalam fungsi bahasa ini adalah makna religius dan estetis (keindahan). Fungsi bahasa dalam sastra lisan dapat mengidentifikasi aspek penggunaannya dalam masyarakat pemiliknya. Dengan mengkaji fungsi bahasa yang terkandung di dalamnya, dapat tercermin pula aspek-aspek makna yang terkandung dalam ungkapannya.

\section{Daftra Pustaka}

Ardianto, Rukmina Gonibala, dan Hadirman. 2019. "Strategi Pelestarian Tradisi Katoba sebagai Media Pendidikan Islam pada Masyarakat Muna di Sulawesi Tenggara”, dalam Jurnal Journal Islamic Education and Policy Vol. 3 No. 1 (2018). Manado: Program Pascasarjana IAIN Manado. http:// journal.iain-manado.ac.id/index.php/jiep/ article/viewFile/849/652 diakses 28 Juli $\underline{2019}$

Berg, R. Van den \& La Ode Sidu Madarafad. 2000. Kamus Muna-Indonesia. Kupang: Artha Wacana Press.

Effendy, Chairil. 2006. Sastra sebagai Wadah Integrasi Bangsa. Pontianak: STAIN Pontianak Press.

Hadirman dan Ardianto. 2016. "Kabhanti Wuna sebagai Media Komunikasi Tradisional dan Tantangannya di Era Globalisasi” dalam 
Jurnal Potret Pemikiran Vol.20, No. 2, JuliDesember 2016. Manado: LP2M IAIN Manado. http://journal.iain-manado.ac.id/ index.php/PP/article/viewFile/751/605 diakses 1 Agustus 2019.

Hadirman, 2016. "Tradisi Katoba sebagai Media Komunikasi Tradisional dalam Masyarakat Muna”, dalam Jurnal Penelitian Komunikasi dan Informasi Publik, Vol. 20 No.1, Agustus 2016. Manado: BPPKI Manado. https:// media.neliti.com/media/publications/ 123946-ID-tradisi-katoba-sebagai-mediakomunikasi.pdf diakses 2 Agustus 2019.

Halliday, M.A.K. 1979. Explorations in the Functions of Language. London: Edward Arnold.

Hardin dan Hadirman, 2017. "Pesan Dakwah Islam dalam Nyanyian Rakyat (Pemaknaan atas Teks-Teks Kabhanti Kantola pada Masyarakat Muna)", dalam Jurnal Aqlam: Journal of Islam and Plurality, Vol. 2, No. 2 2017. Manado: FUAD IAIN Manado. http://journal.iainmanado.ac.id/index.php/AJIP/article/ download/525/436 diakses 28 Agustus 2019.

Hoed, B.H. "Komunikasi Lisan sebagai Dasar Tradisi Lisan", dalam Metodologi Penelitian Tradisi Lisan” Pudentia (ed.). Jakarta: Yayasan Asosiasi Tradisi Lisan.

Hutomo, Suripan Sadi. 1991. Mutiara yang Terlupakan, Pengantar Studi Sastra Lisan. Surabaya: HISKI Jawa Timur.

Hymes, Dell. 1974. "Way of Speaking” dalam Richard Bauman \& Sherzer (Eds.).
Explorations in the Ethnography of Speaking. $\mathrm{P}$ 433-451. Cambridge: Cambridge University Press.

Jendra, I Wayan. 1999. Etika Berbicara dalam Sastra Hindu (Analisis Religiososiolinguistik). Denpasar: Universitas Udayana.

Kadarisman, A Effendi. 2008. "Sketsa Puitikan Jawa: dari Rima Anak-Anak sampai Filsafat Bahasa", dalam Metodologi Penelitian Tradisi Lisan" Pudentia (ed.). Jakarta: Yayasan Asosiasi Tradisi Lisan.

Koster, G.L. 2008. "Kaca Mata Hitam Pak Mahmud Wahid atau Bagaimanakah Meneliti Puitika Sebuah Sastra Lisan" dalam dalam Metodologi Penelitian Tradisi Lisan" Pudentia (ed.). Jakarta: Yayasan Asosiasi Tradisi Lisan. Luardini, Maria Arina. 2007. "Fungsi Bahasa dalam Legenda Rakyat Kalimantan”, dalam Jurnal Linguistika, Vol. 16, No.30 Maret 2007. Denpasar: Program S2 dan S3 Linguistik Universitas Udayana.

Soga, Zainuddin dan Hadirman. 2018. "Semiotika Signifikansi: Analisis Struktur dan Penerapannya dalam Alquran" dalam Jurnal Aqlam Vol.3 No.1( 2018). Manado: FUAD IAIN Manado; in http://journal.iain-manado.ac.id/ index.php/AJIP/article/view/632 diakses 28 Agustus 2019.

Zaimar, Okke K.S. 2008. "Metodologi Penelitian Sastra Lisan", dalam Metodologi Penelitian Tradisi Lisan” Pudentia (ed.). Jakarta: Yayasan Asosiasi Tradisi Lisan. 